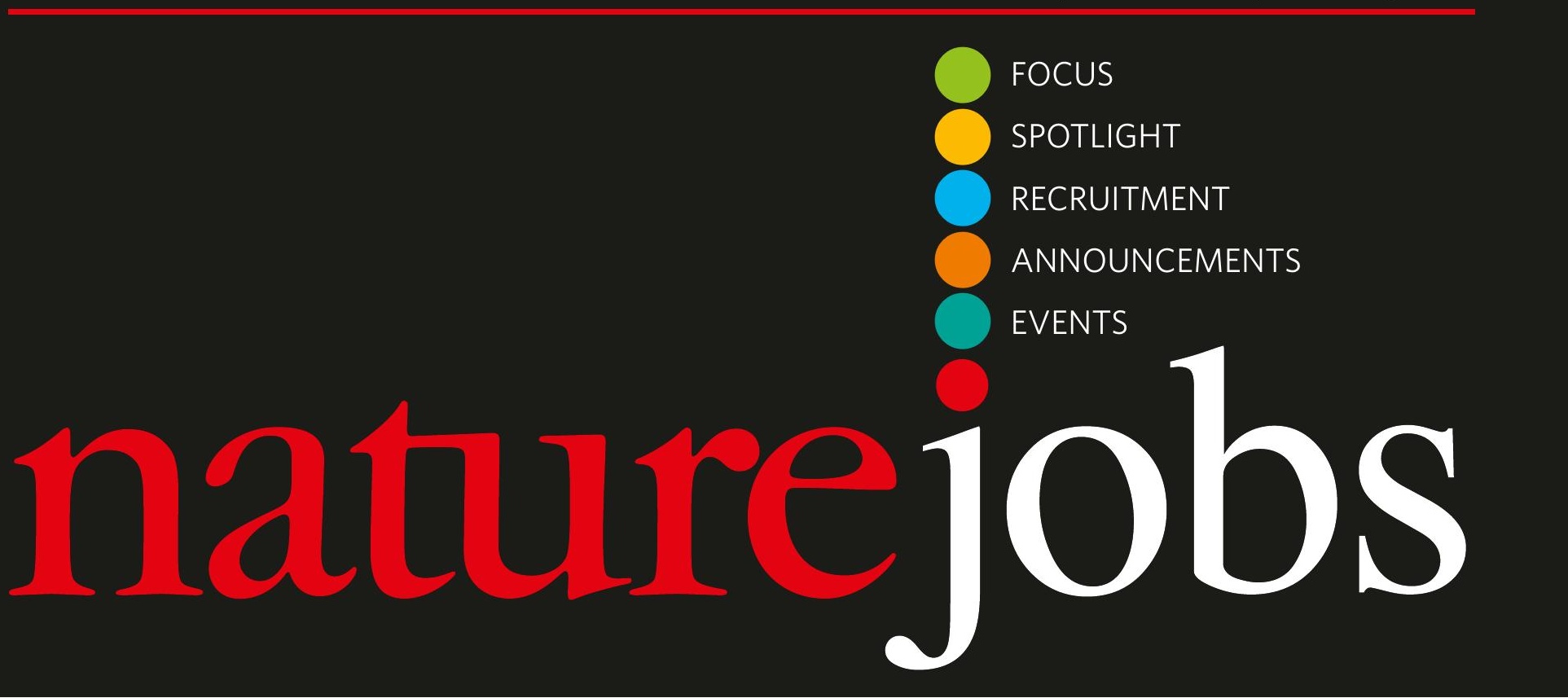

\title{
Speaking in tongues
}

The recent case of a Chinese graduate student who was almost expelled from Yale University and sent home despite passing her qualifying exams (see Nature 438, $278-279 ; 2005)$ raises some difficult questions. How much responsibility should foreign students shoulder to ensure that they are prepared for work in their temporary home? And to what extent should the host institution put itself out to ensure their guests' success?

Academic credentials and scientific skills are clearly prerequisites for visiting students, but what about language skills? To find out more, Naturejobs conducted a swift survey of its readers. The vast majority of respondents (79\%) said the onus should be on the students to improve their language skills, with 39\% saying that the visitors should take an intensive language course before heading abroad. Only $11 \%$ believed that foreign graduate students should ask their adviser or their peers at the host institution for help overcoming the language barrier.

At first glance, it seems reasonable to expect incoming students to bone up on the language they will be working in before they arrive. But the question really centres on the

CONTACTS

Publisher: Ben Crowe

Editor: Paul Smaglik

Assistant Editor: Corie Lok

European Head Office, London

The Macmillan Building, 4 Crinan Street London N1 9XW, UK

Tel: +44 (0) 2078434961

Fax:+44 (0) 2078434996

e-mail:naturejobs@nature.com

Naturejobs Sales Director: Nevin Bayoumi (4978)

European Sales Manager:

Andy Douglas (4975)
Natureevents: Sille Opstrup (4994) UK/RoW/Ireland/Italy:

Nils Moeller (4953)

Irene Viglia-Atton (4944)

Scandinavia/Spain/Portugal:

Evelina Rubio Håkansson (4973)

France/Switzerland/Belgium:

Amelie Pequignot (4974)

Germany/Austria/The Netherlands:

Reya Silao (4970)

Advertising Production Manager:

Billie Franklin

To send materials use London

address above.

Tel: +44 (0) 2078434814 social contract between an institution and its students. In many instances, universities not only provide education for foreign graduates, they also benefit from the relatively cheap research and teaching support these students provide. In addition, institutions in the United States and Europe are increasingly viewing foreign scientists as a key component in their success - so it seems only fair for the students to get help acclimatizing in return.

Some places already take this approach in terms of scientific acumen. The European Molecular Biology Laboratory in Heidelberg, Germany, for instance, attracts students from many different education systems, and works to bring everyone to the same scientific level within their first year. Maybe institutions should now be doing the same sort of thing for language and teaching skills.

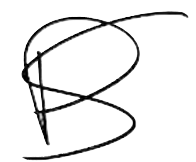

\section{Paul Smaglik, Naturejobs editor}

NY 10013-1917

Tel: +18009897718

Fax: +18009897103

e-mail: naturejobs@natureny.com

US Sales Manager: Peter Bless

Japan Head Office, Tokyo

Chiyoda Building,

2-37 Ichigayatamachi,

Shinjuku-ku,

Tokyo 162-0843

Tel: +81332678751

Fax: +81332678746

Asia-Pacific Sales Director: Rinoko Asami

e-mail: r.asami@naturejpn.com 